\title{
Financial and Performance Analyses of Microcontroller Based Solar-Powered Autorickshaw for a Developing Country
}

\author{
Abu Raihan Mohammad Siddique ${ }^{1}$ and M. Shamim Kaiser ${ }^{2}$ \\ ${ }^{1}$ Department of Electrical, Electronic \& Communication Engineering, Military Institute of Science and Technology (MIST), \\ Mirpur, Dhaka 1216, Bangladesh \\ ${ }^{2}$ Institute of Information Technology, Jahangirnagar University, Savar, Dhaka 1342, Bangladesh
}

Correspondence should be addressed to Abu Raihan Mohammad Siddique; raihansiddique48@gmail.com

Received 28 February 2016; Revised 13 June 2016; Accepted 30 June 2016

Academic Editor: Andrzej Bartoszewicz

Copyright (c) 2016 A. R. M. Siddique and M. S. Kaiser. This is an open access article distributed under the Creative Commons Attribution License, which permits unrestricted use, distribution, and reproduction in any medium, provided the original work is properly cited.

\begin{abstract}
This paper presents a case study to examine the economic viability and performance analysis of a microcontroller based solar powered battery operated autorickshaw (m-SBAR), for the developing countries, which is compared with different types of rickshaws such as pedal rickshaw (PR), battery operated autorickshaw (BAR), and solar-powered battery operated autorickshaw (SBAR), available in Bangladesh. The BAR consists of a rickshaw structure, a battery bank, a battery charge controller, a DC motor driver, and a DC motor whereas the proposed m-SBAR contains additional components like solar panel and microcontroller based DC motor driver. The complete design considered the local radiation data and load profile of the proposed m-SBAR. The Levelized Cost of Energy (LCOE) analysis, Net Present Worth, payback periods, and Benefit-to-Cost Ratio methods have been used to evaluate the financial feasibility and sensitivity analysis of $\mathrm{m}$-SBAR, grid-powered BAR, and PR. The numerical analysis reveals that LCOE and Benefit-to-Cost Ratio of the proposed m-SBAR are lower compared to the grid-powered BAR. It has also been found that microcontroller based DC motor control circuit reduces battery discharge rate, improves battery life, and controls motor speed efficiency.
\end{abstract}

\section{Introduction}

Human energy driven pedal rickshaws (PRs) are a common mode of transport in some of the developing countries. About $38.3 \%$ of the total population in Bangladesh prefers to travel using PR [1]. These have gained acceptance especially among the middle-class and lower-middle-class family of this country as those offer lower travel cost compared to four-stroke autorickshaw and taxi. Moreover, these are environmentally friendly, low maintenance vehicles. The rickshaw has also been a good source of income of the rickshaw puller.

A traditional human-driven PR converts human labor into rotational energy that produces translational motion. The mean values of energy expenditure of pulling a PR vary from $23.5 \pm 2.66 \mathrm{~kJ} / \mathrm{min}$ to $25.35 \pm 1.51 \mathrm{~kJ} / \mathrm{min}$ [2]. Relative cardiac strain and cardiac cost indicate that this job is "heavy" to "very heavy" [3]. Rickshaw puller is exposed to air pollutants and their heavy physical activity for more than 8 hours generates reactive oxygen species. Both of these potentially can damage DNA structure of the human body [4].

The battery operated autorickshaw (BAR) is equipped with additional components like a battery bank, a DC motor, and a motor driving circuit. It can eliminate this strenuous physical labor of the PR puller. The stored electrical energy from a battery bank runs the motor. But the battery bank needs to be charged by supply lines of the national grid where Bangladesh Government is giving several hundred million taka (TK) as subsidy. A survey of "High Beam research" in January 2012 found that there were around fifty thousand BARs in Dhaka city [5]. This figure rose to half million in the following six months. They also predicted that this figure would be more than two million in December 2014. If this rate continues, a large amount of power will be used for charging up the battery banks of these rickshaws. Several surveys showed that BARs consume at least 200-250 MW 


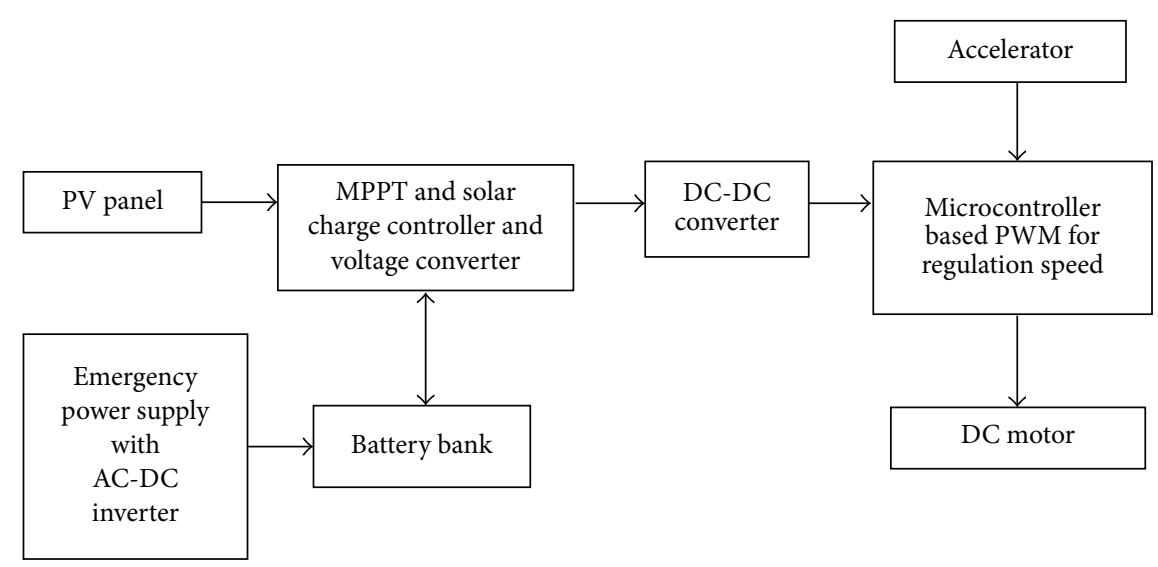

FIgURE 1: Microcontroller based m-SBAR.

of electricity every day to recharge their batteries from the national grid which is not expected [6].

The motivation behind this work is to design a standalone rooftop photovoltaic (PV) power system for BAR, thereby producing this additional power demand by PV system. PV is an alternative source of electrical energy. In contrast to fossil fuel, this is renewable and environmentfriendly. The primary obstacle to raise the use of PV system is the high capital cost. But the solar radiation received at the ground surface is potentially high in Bangladesh. The bright sunshine hours vary from 4 to 10 hours/day and the daily solar radiation ranges from 4 to $6.5 \mathrm{kWh} / \mathrm{m}^{2}$ and has been received on the horizontal surface in Bangladesh [7, 8].

The solar-powered battery operated autorickshaw (SBAR) was first introduced in England in 2000 by Collinada Ltd., a British company along with Indian sponsor [9]. In 2003, they were commercially launched on the market, but SBAR was poorly designed and less energy efficient. London based research and design company "Solar Lab" worked on a SBAR that would be the first human powered hybrid vehicle in 2008 . Around $80 \%$ of the total power is sourced by solar energy and rest of the energy is driven by the pedal. The first successful SBAR was introduced at Chandigarh, India, in 2008 which was designed by the Council of Science and Industrial Research (CSIR) and named Soleckshaw [10]. In 2012, it was commercially launched. The Soleckshaw is run by a brushless direct current (BLDC) motor. In Bangladesh, BeevaTech Ltd. launched SBAR in January 2012 [11]. It is operated by 48 -volt battery, charge controller, speedometer, and motor and named it "Pedicab Rickshaw."

In this work, we have proposed a microcontroller based $\operatorname{SBAR}(\mathrm{m}-\mathrm{SBAR})$, where the speed and duty cycle of the motor are controlled by a microcontroller, thereby increasing the driving hour of the rickshaw. The financial and sensitivity analyses have been done using Life Cycle Cost (LCC), Net Present Worth (NPW), Benefit-to-Cost Ratio (BCR), and payback periods (PP) methods with various parameters. Finally, the performance of the m-SBAR has been evaluated.

The rest of the sections are as follows: Section 2 introduces m-SBAR model, Section 3 discusses energy scenario and solar energy of Bangladesh, Section 4 depicts system's cost assumption, Section 5 shows project feasibility matrices and analysis, Section 6 includes numerical analysis, and finally the work is concluded in Section 7.

\section{Proposed Solar-Powered Rickshaw Model}

The main components of proposed m-SBAR are a solar panel, microcontroller based Maximum Power Point Tracker (MPPT) with charge controller, battery bank, and microcontroller based DC motor controller, DC motor, and rickshaw structure available in the local market. Figure 1 shows the block diagram of our proposed m-SBAR.

The solar panel is a package that consists of photovoltaic cells, which converts solar radiation into electrical energy. Energy from sunlight is stored in the lead acid battery bank, which is controlled by a microcontroller based charge controller. The charge controller tracks the maximum power point (MPP). The lead acid battery is considered because of its low cost, reliability, low input impedance, and ability to deliver very high current. The backup system is necessary as PV system only generates electricity when the sun is shining. Battery charge controller also protects the batteries from excessive discharging. Microcontroller based motor driving circuit controls the duty cycle of the motor. There are two ways to move a vehicle whether to use a DC motor or a stepper motor. DC motors are always preferred over stepper motor when it comes to speed, size, and cost. Figure 2 shows a front view of the proposed m-SBAR model.

In the existing SBAR, there is no speed controller. As a result, it causes unbalancing at high speed and consumes same power continuously. The existing old version of charge controller is not appropriate for this type of vehicle. In our proposed model,

(1) a microcontroller based maximum power point tracking has been designed,

(2) a microcontroller controlled DC motor driving circuit has been included,

(3) a hydraulic disc braking system has been added,

(4) the suspension system has been added to minimize the taxiing, 


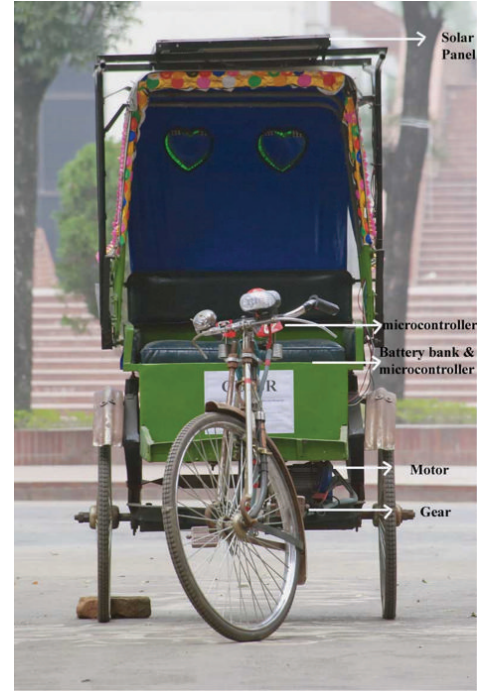

FIgURE 2: Photograph of the proposed m-SBAR.

(5) some of the constructional designs have been changed such as spring suspension that has been added to give comfort to the passenger and two gears have also been added to make a mechanically efficient system,

(6) a speed limit of less than $20 \mathrm{~km} /$ hour has been imposed for safety purposes.

There are some factors which have to be considered for evaluating the performance of the proposed model. Although in most of the cases, the solar panel is tilted at latitude of the area under consideration, the panel tilted at latitude will increase the effective air resistance on the rickshaw while moving in the forward direction. Hence, the angle of tilt is chosen to be $0^{\circ}$. If the output power of the solar panel is $P_{\mathrm{pv}}$, driving hour is $H_{d}$, parking hour is $H_{p}$, the average sun hour is $H_{s}$, and $\varepsilon$ is constant, then total energy, denoted by $E_{\mathrm{pv}}$, is

$$
E_{\mathrm{pv}}=P_{\mathrm{pv}}\left[\varepsilon H_{p}+(1-\varepsilon) H_{d}\right] \text {, }
$$

where

$$
\varepsilon H_{p}+(1-\varepsilon) H_{d}=H_{s} .
$$

$E_{\mathrm{pv}}$ is comprised of two energy terms: the first one is the contribution when in parking mode and the second term is for the duration when in driving mode. This is a good approximation since when in parking mode, the energy generated is stored in the battery, whereas, when in driving mode, the energy is supplied to the load directly instead. The total required watt-peak of the PV array's capacity, denoted by $\Gamma_{\text {req }}$, can be written as

$$
\Gamma_{\text {req }}=\frac{L_{\text {daily }} \times 1.3}{\psi_{\text {pv }}},
$$

where $L_{\text {daily }}$ is the daily energy demand of the load, $\psi_{\mathrm{pv}}$ is the panel generation factor, and the sizing of MPPT takes the load energy multiplied by the factor of 1.3 as per rule of thumb [12]. The total number of required PV array sizing can be calculated by

$$
\begin{aligned}
& N_{\text {SS }}=\frac{V_{s}}{V_{\mathrm{pv}}}, \\
& N_{\mathrm{SP}}=\frac{\Gamma_{\text {req }}}{\Gamma_{\mathrm{pv}}},
\end{aligned}
$$

where $N_{\mathrm{SS}}$ and $N_{\mathrm{SP}}$ are the number of solar modules in series and parallel, respectively, $V_{s}$ and $V_{\mathrm{pv}}$ are nominal system voltage and the output voltage of $\mathrm{PV}$, respectively, and $\Gamma_{\mathrm{pv}}$ is the rated capacity of the $\mathrm{PV}$ array (in watt-peak). The required capacity of the battery, $L_{B}$, can be calculated according to the following relation $[13,14] . L_{B}$ is given by

$$
L_{B}=\frac{D_{r} \times L_{\text {daily }}}{u_{\max } \times \eta_{B}},
$$

where $D_{r}$ is the reserved day(s), $u_{\max }$ is the maximum percentage depth of discharge, $L_{\text {daily }}$ is the daily energy demand of the load, and $\eta_{B}$ is the battery efficiency. The expression for number of required batteries in series and parallel can be calculated as

$$
N_{\text {BS }}=\frac{V_{L}}{V_{B}},
$$

where $N_{\mathrm{BS}}$ is the number of batteries in series, $V_{L}$ is nominal load voltage, and $V_{B}$ is the nominal battery bank voltage:

$$
N_{\text {BP }}=\frac{L_{B}}{L_{B}{ }^{s}},
$$

where $N_{\mathrm{BP}}$ is the number of batteries in parallel and $L_{B}{ }^{s}$ is the battery capacity of each battery unit. There are mainly two resistive forces which act on the rickshaw. These are drag force and frictional force. The drag force is one kind of mechanical force which opposes an incoming object through the air. It is generated by the body of the object when the object interacts with any other substance like air or fluid. Air resistance is approximated by the following formula:

$$
\bar{F}_{\text {drag }}=\frac{1}{2} C_{d} A \rho_{a} \bar{v}^{2},
$$

where $C_{d}$ is the coefficient of friction (for low speed vehicles, it is assumed to be $0.3[15]), A$ is a frontal area of the rickshaw, $\rho_{a}$ is the density of air $\left(1.29 \mathrm{~kg} / \mathrm{m}^{3}\right)$, and $v$ is the speed of the rickshaw in $\mathrm{m} / \mathrm{s}$ (not considering the speed of wind). The frictional force, denoted by $F_{\mathrm{rr}}$, can be approximated by

$$
\bar{F}_{\mathrm{rr}}=g \bar{W} C_{\mathrm{rr}},
$$

where $g$ is the gravitational acceleration $\left(9.8 \mathrm{~ms}^{-2}\right)$ and $C_{\mathrm{rr}}$ is the rolling resistance and $W$ is the weight of the rickshaw. The weight distribution dramatically affects the maximum traction force per wheel. While braking, the traction force is replaced by a braking force, which is oriented in the opposite 


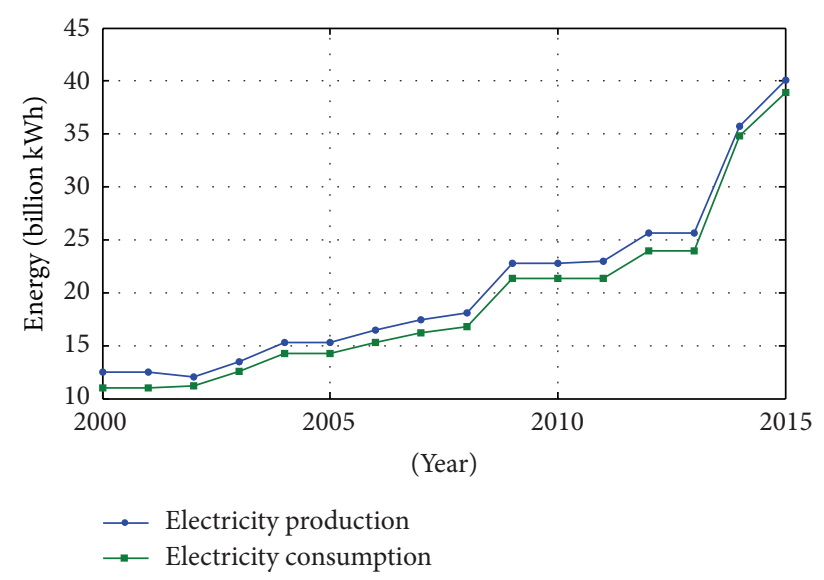

FIGURE 3: Energy generation and consumption over different years.

direction to the driving force. The force due to gravitational pull on a tilted surface, $F_{g}$, can be expressed by

$$
\bar{F}_{g}=m g \operatorname{Sin} \theta,
$$

where $m$ is the mass of the object, $g$ is the gravitational constant $\left(9.8 \mathrm{~ms}^{-2}\right)$, and $\theta$ is the angle of inclination of the plane. The total longitudinal force is then the vector sum of these forces:

$$
\bar{F}_{\text {Total }}=\bar{F}_{\text {drag }} \pm \bar{F}_{\text {rr }} \text {. }
$$

The required power to oppose all the resistive forces acting on the rickshaw will be

$$
P_{r}=\bar{F}_{\text {Total }} v
$$

\section{Energy Scenario and Solar Energy}

The electricity development is required to accelerate access and attain economic development for any country. Power sector plays a key role in the development of a country. For a third world developing country like Bangladesh, this sector is still under the development process. It was reported that on 1 July 2015 the maximum electricity generation was raised to $11,000 \mathrm{MW}$ against the demand of $6666 \mathrm{MW}$. Due to the poor transmission and system losses, the increased power production was still not able to meet the demand. The above statistics gives a picture of the fragile power and electricity conditions of the country [16]. Figure 3 shows the electricity production and consumption (in billion $\mathrm{kWh}$ ) curves for different years. The per capita energy consumption of Bangladesh is one of the lowest (around $265 \mathrm{kWh}$ ) in the world. In 2014, almost $59 \%$ of our population had access to electricity [17]. The increase of energy demand over different years is shown in Figure 4.

In Bangladesh, electrical energy is generated by using gas turbines heated by burning fossil fuels (natural gas, gasoline, etc.) and hydropower stations. The demand for power is increasing rapidly since Bangladesh has a very fast increasing population rate. As a consequence, the country's

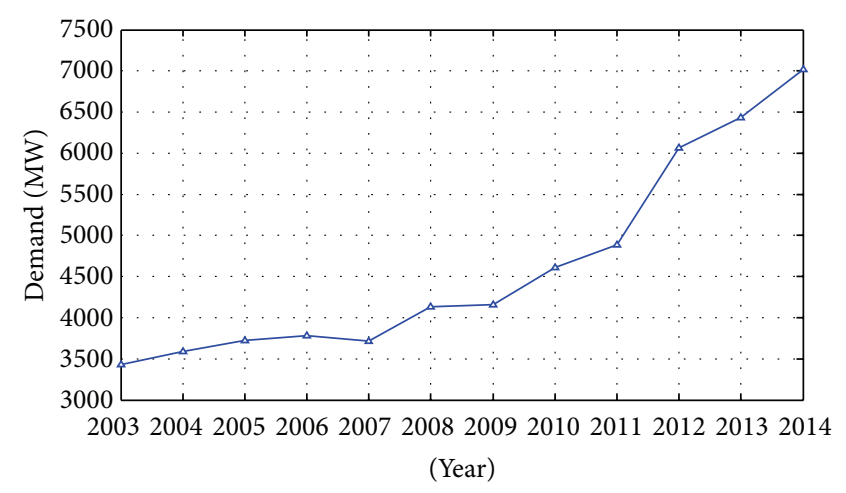

FIGURE 4: Increase of energy demand over different years.

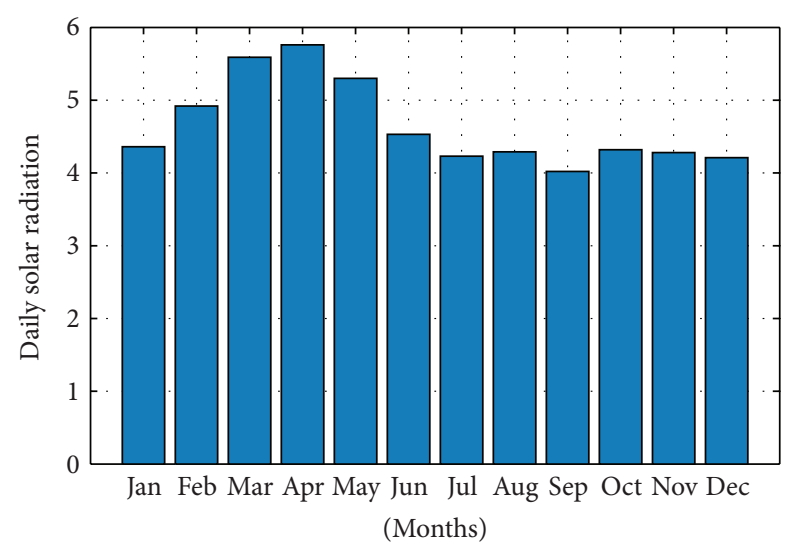

FIGURE 5: Monthly average daily solar radiation data.

energy demand is actually growing annually $12 \%$ and as per government's estimation of 7\% [16]. Use of renewable sources of energy, such as solar, wind, tides, biofuel, and geothermal heat, can be utilized to meet this demand.

Solar energy is a great opportunity for solving power crises in Bangladesh. Some studies indicate that if solar energy is adopted, as much as $10,000 \mathrm{MW}$ daily of solar electricity can be generated in short and medium runs which are equivalent to almost twice the total amount of electricity produced and supplied to the national grid. Bangladesh is situated between $20.30^{\circ}$ and $26.38^{\circ}$ north latitude and $88.04^{\circ}$ and $92.44^{\circ}$ east longitude. At this position, Figure 5 unfolds the data of daily solar radiation of Dhaka city [18]. Thus, $\mathrm{m}$ SBAR is the good option to replace PR and BAR.

\section{Assumption for Financial Analysis}

For the financial feasibility analysis, five different types of rickshaws were considered as given below:

(1) Case A: PR.

(2) Case B: BAR which is charged by the national grid.

(3) Case C: SBAR.

(4) Case D: BAR which is charged by the national grid and government that is not giving subsidy in the electricity generation.

(5) Case E: m-SBAR. 
The following is the assumptions considered for investment evaluation analysis:

(1) In Bangladesh, electric power is generated by gas, hydro, steam-turbine, and diesel power plants. All the generation units are interconnected through a national grid. As a result, the cost of per unit electricity is not uniform. The average per unit (kWh) electricity generation cost is around 0.183 USD and the average sales rate is 0.06 USD and for small business, it is 0.09 USD which is considered in our proposed model [19].

(2) Greenhouse gas (GHG) emission reduction cost is calculated using RET Screen Software, which is a free clean energy software package developed by the Government of Canada. RET Screen Software calculates reductions in greenhouse gas (GHG) emissions which are 169 USD yearly.

(3) Annual nonrecurring cost is 41 USD estimated for all cases.

(4) The investment costs for Case B, Case C, Case D, and Case E are 725.21 USD, 835.8 USD, 725.21 USD, and 848.66 USD considered, respectively.

(5) For Case B and Case D, the daily saving is 7.72 USD, whereas, for Case $\mathrm{C}$ and Case E, the daily savings are 8.36 USD and 9 USD, respectively.

\section{Project Feasibility Matrices}

An analysis is required to evaluate the financial feasibility of the m-SBAR. The analysis includes the Life Cycle Cost analysis of the entire system, net present value (NPV), and Levelized Cost of Energy (LCOE) that were considered to determine whether an investment is economically feasible or not fulfilling the required criteria for meeting the user demands.

5.1. Net Present Value. Net present value (NPV) is one of the commonly used matrices to compare projects with different capital and operating cost streams. It includes the present discounted value of all project cost and revenues. If the discount rate is $d$, the cost of the project during year $n$ is $C_{n}$ and the revenues of the project during year $n$ are $B_{n}$, and then the NPV can be calculated as

$$
\mathrm{NPV}=\sum_{n=0}^{N} \frac{B_{n}-C_{n}}{(1+r)^{n}}=\sum_{n=0}^{N} \frac{C_{F}(1+\iota)^{n}}{(1+r)^{n}},
$$

where $C_{F}$ is the annual cash flow, $\iota$ is the interest rate, $n$ is the number of years, and $r$ is the rate of return.

5.2. Levelized Cost of Energy. Levelized Cost of Energy (LCOE) is mostly used as economic feasibility evaluation parameter, for assessing the viability of energy project. It is the ratio of the energy cost to energy output for which the NPV of the investment is zero. The main limitation of this approach is that it does not include risk and different actual financial methods (Branker, Pathak). The LCOE is calculated as

$$
\mathrm{LCOE}=\frac{\sum_{n=0}^{N} \mathrm{LCC}_{n}}{\sum_{n=0}^{N} E_{n}},
$$

where $\mathrm{LCC}_{n}$ is the Life Cycle Cost in the year $n$ of the project and $E_{n}$ is the energy produced in the year $n$.

The LCC consists of the capital cost, total operation, and maintenance cost and total replacement cost over the whole lifetime. Based on $[1,2]$, the LCC, denoted by LCC, is used to find the optimal configuration of energy project and it is calculated as

$$
\mathrm{LCC}=C_{c}+\sum_{n=1}^{N} C_{o \& m}^{n}+\sum_{n=1}^{N} C_{r}^{n},
$$

where $N$ is the lifetime of the system (in years), $C_{c}$ is the capital cost of the system, $C_{o \& m}^{n}$ is the annual operation and maintenance cost of year $n$, and $C_{r}^{n}$ is the replacement cost of the system.

5.3. Payback Period (PP) Method. This method calculates the number of years needed for an investor to recover the investment. This payback period is compared with maximum acceptable payback period determined by the investor. If the payback period exceeds the maximum limit, then the project is unacceptable. The payback period can be expressed as

$$
\mathrm{PP}=\frac{\log \left[C_{c} /\left(A_{o}((1+\varepsilon) /(\varepsilon-\iota))+1\right)\right]}{\log [(1+\varepsilon) /(1+\iota)]},
$$

where $C_{c}$ is the capital cost, $A_{o}$ is the total cost, $\varepsilon$ is the inflation rate, and $\iota$ is the interest rate.

5.4. Benefit-to-Cost Ratio (BCR) Method. Public projects are evaluated using this investment evaluation method. The BCR is defined as

$$
\mathrm{BCR}=\frac{A_{s}+\mathrm{GHG}}{\mathrm{LCC}},
$$

where $A_{s}$ is the annual saving and GHG is the cost of greenhouse gas.

\section{Numerical Results}

Table 1 shows the assumptions which have been made on the basis of present market prices to determine the financial feasibility of the proposed m-SBAR [11, 19].

The proposed PV module consists of 4 individual panels connected in series, each of which is rated at $12 \mathrm{~V}$ and $100 \mathrm{~W}$. The motor requires runs at $48 \mathrm{~V}$ which necessitates the cascaded configuration of the panels. The initial cost of the modules is $280 \mathrm{USD}$, and its operation and maintenance cost is 5.6 USD, with the total NPC (for the PV module only) of 285.6 USD. The project lifetime is the time period over which the costs of the system are considered. PV is the major component of this system and its lifetime is 20 years, which makes it compulsory that the lifetime of the project be 
TABLE 1: Economic factors to determine financial feasibility.

\begin{tabular}{lc}
\hline Economic factors & Units \\
\hline Operation and maintenance cost & $5 \%$ \\
Installation cost & $\$ 3 /$ day \\
Unit cost of the solar panel (\$/Watt-peak) & $\$ 0.6$ \\
Inflation rate $(\varepsilon)$ & $5 \%$ \\
General escalation $(\mathrm{GE})$ & $3 \%$ \\
Discount rate $(\delta)$ & $7 \%$ \\
LCC nonrecurring cost factor & 0.565 \\
Interest rate $(\iota)$ & $7 \%$ \\
Project lifetime $(\mathrm{n})$ & 20 years \\
\hline
\end{tabular}

TABLE 2: Benefit-to-Cost Ratio for four different cases.

\begin{tabular}{ccccc}
\hline & Case B & Case C & Case D & Case E \\
\hline Benefit-to-Cost Ratio & 1.59 & 6.69 & 1.22 & 7.22 \\
\hline
\end{tabular}

TABLE 3: Payback period for four different cases.

\begin{tabular}{lcccc}
\hline & Case B & Case C & Case D & Case E \\
\hline Payback period (years) & 2.21 & 2.34 & 2.20 & 2.10 \\
\hline
\end{tabular}

TABLE 4: LCOE for four different cases.

\begin{tabular}{lcccc}
\hline & Case B & Case C & Case D & Case E \\
\hline LCOE $(\mathrm{USD} / \mathrm{kWh})$ & 0.14 & 0.06 & 0.26 & 0.05 \\
\hline
\end{tabular}

considered to be 20 years as well. The Hamko solar battery is rated at $12 \mathrm{~V}$ and $60 \mathrm{Ah}$. The battery bank consists of four batteries with an initial cost of 272 USD. The lifetime of battery bank is 5 years. Over the project lifetime of 20 years, the replacement, and operation and maintenance costs add an additional 438.17 USD to the initial cost. The converter is rated at $1 \mathrm{~kW}$. Its initial cost is $60 \mathrm{USD}$, and its operation and maintenance cost is 2.5 USD.

Tables 2, 3, and 4 show Benefit-to-Cost Ratio, payback period, and LCOE, respectively, for Case B, Case C, Case D, and Case E. It has been seen that Benefit-to-Cost Ratio of Case $\mathrm{E}$ is the highest among all the cases whereas the payback period for the proposed system is the lowest compared to the other cases. It has also been found that the LCOE of the proposed rickshaw (i.e., Case $\mathrm{E}$ ) is the lowest.

Figure 6 shows the effect of interest rate on payback period. The payback period increases linearly with the increase of interest rate. The payback period for the proposed case is the lowest for Case E. Figure 7 shows the cash flow analysis for the four different cases.

Figure 8 shows the B-to-C analysis for the four different cases. For Case E the B-to-C ratio is the highest and the B-to$\mathrm{C}$ reduces with the increase in interest rate. For the proposed model, $C_{d}=0.3, A=1.01 \mathrm{~m} / \mathrm{s}$, and $\rho=1.29 \mathrm{~kg} / \mathrm{m}^{3}$. Substituting these values in (8), we get different values of required power for various speeds which can be calculated using (11). Table 4 refers to different $F_{\text {drag }}$ for different speed obtained.

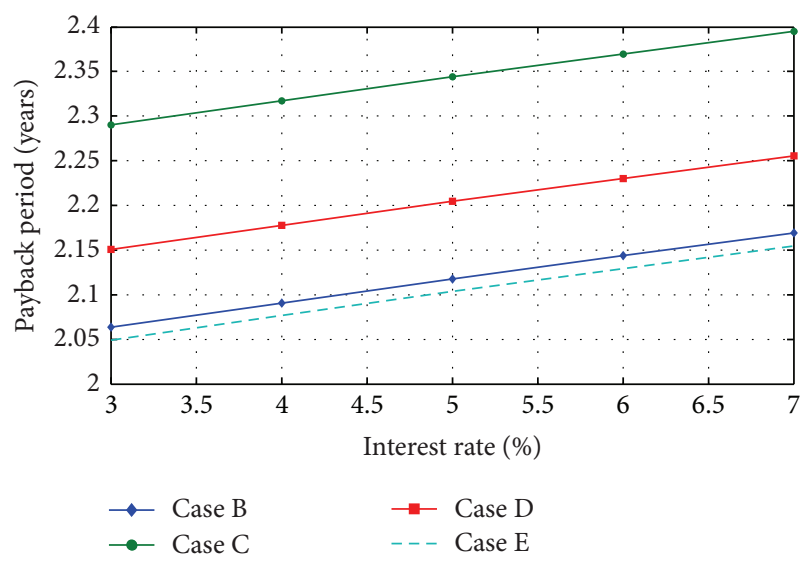

FIGURE 6: Effect of interest rate on payback period for four different cases.

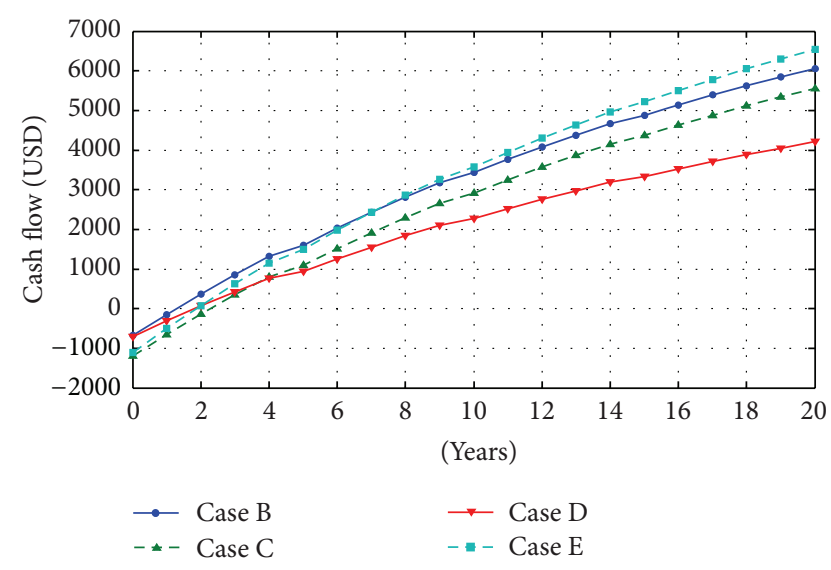

FIgURE 7: Effect of interest rate on cash flow analysis for four different cases.

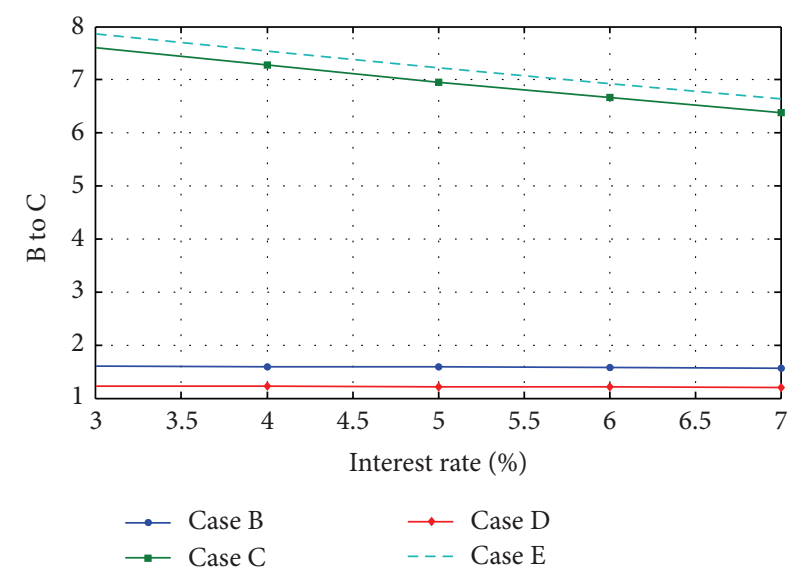

Figure 8: Effect of interest rate on Benefit-to-Cost Ratio for four different cases.

Again, the weight of our model is around $150 \mathrm{~kg}$ (including rickshaw puller, structure of rickshaw, $\mathrm{PV}$ module, and other components) and $C_{\mathrm{rr}}=0.3$. Table 5 gives total resistive forces and the required power $P_{r}$. 
TABLE 5: Different drag forces with the variation of speed.

\begin{tabular}{lccc}
\hline Speed $(\mathrm{Km} / \mathrm{h})$ & $F_{\text {drag }}(\mathrm{N})$ & $F_{\text {Total }}(\mathrm{N})$ & $P_{r}(\mathrm{~W})$ \\
\hline 3 & 0.137 & 441.59 & 367.99 \\
5 & 0.381 & 441.83 & 613.65 \\
8 & 0.975 & 442.42 & 983.17 \\
10 & 1.523 & 442.97 & 1230.48 \\
12 & 2.193 & 443.64 & 1478.81 \\
15 & 3.426 & 444.88 & 1853.68 \\
20 & 6.091 & 447.54 & 2486.34 \\
\hline
\end{tabular}

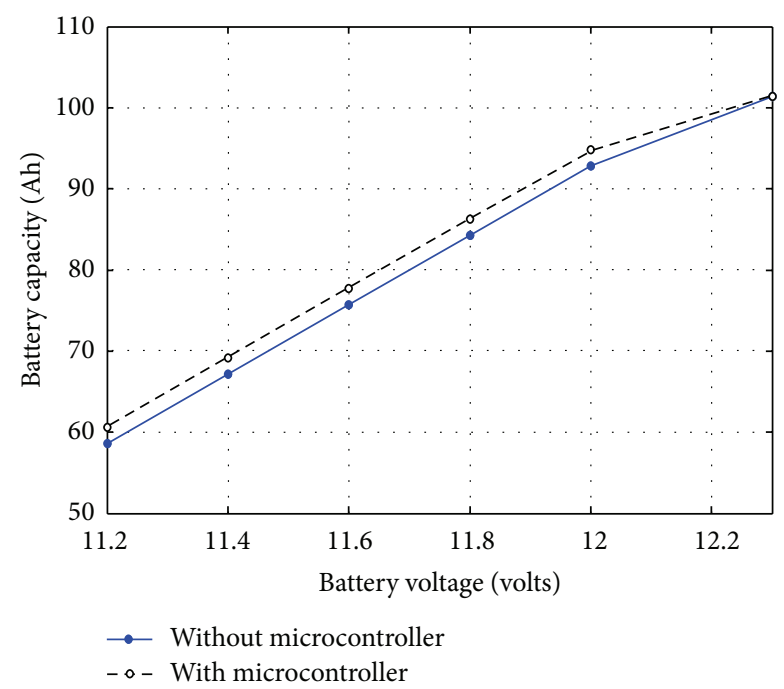

FIGURE 9: Relationship between battery capacity and battery voltage.

Figure 9 shows the relationship between battery capacity and battery voltage. The figure depicted that battery discharging time has risen due to the use of microcontroller to drive DC motor of the proposed $\mathrm{m}$-SBAR.

In the proposed $\mathrm{m}$-SBAR a $300 \mathrm{~W}$ DC motor was used. The voltage rating is $48 \mathrm{~V}$ and current rating is $3.25 \mathrm{~A}$. If the average time of running this motor is about 6 hours (h), then the average energy required to drive the motor, denoted by $E_{m}$, is

$$
E_{m}=3.25 \mathrm{~A} \times 6 \mathrm{~h} \times 48 \mathrm{~V}=936 \mathrm{Wh} .
$$

Due to the space constraint on the rooftop and to have a good balance in case of speed more than $15 \mathrm{~km} / \mathrm{h}$, we have installed two solar panels. The electrical specification of the solar panel is $100 \times 2$, that is, 200 watt. If they are connected in series, then the nominal system voltage is 24 volts and measured current is found to be $8.33 \mathrm{~A}$. Then ampere-hour ( $\mathrm{Ah}$ ) produced by solar panel $E_{\mathrm{pv}}$ is

$$
E_{\mathrm{pv}}=8.33 \mathrm{~A} \times 6 \mathrm{~h} \times 12 \mathrm{~V} \times 2=1199.52 \mathrm{Wh} .
$$

Using (5) and (6), battery capacity and number of batteries in series are 27.78 and 4 , respectively. The battery capacity is $48 \mathrm{~V}, 4.5 \mathrm{~A}$; then energy supply by the battery is $1296 \mathrm{~J}$ (i.e., $40 \times 12 \times 4$ ). Figure 10 shows the effect of motor speed on the

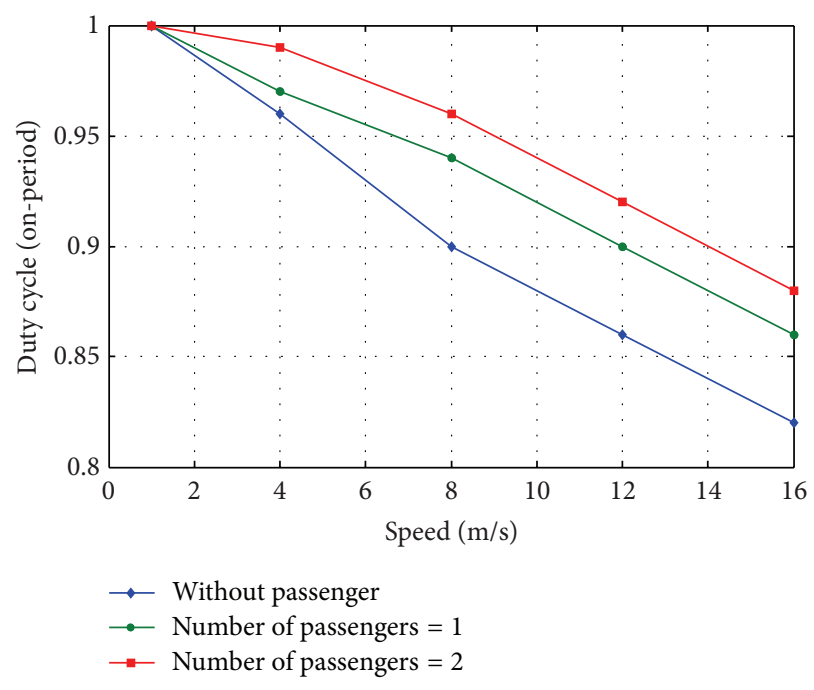

FIGURE 10: Effect of speed on the on-period of the duty cycle cases.

on-period (i.e., duty cycle) generated by PIC microcontroller. It has been found from the practical measurement that the duty cycle depends on the frictional force. The increase of the speed of the motor reduces the on-period of the DC motor. When the number of passengers increases the more energy is required to overcome the frictional force; thus, the duty cycle is increasing.

The Hamco solar battery is rated at $12 \mathrm{~V}$ and has a capacity of $80 \mathrm{Ah}$. Four batteries initially cost $\$ 250$ and the replacement cost and the operation and maintenance cost add a further $\$ 11,927$ and $\$ 55,056$, respectively. The converter is rated $0.5 \mathrm{~kW}$. Its initial cost is $\$ 50.5$, and its operation and maintenance cost is $\$ 11.5$, with the total NPC (for the converter only) of $\$ 61.5$.

\section{Conclusion}

This paper presents the technofinancial feasibility study of m-SBAR. The hourly average solar radiation data for the solar photovoltaic unit and the DC motor are used to predict the general performance of the generating system. A detailed economic analysis has also been done for the solar photovoltaic unit. Based on the rooftop space a PV system of $400 \mathrm{~W}$ is enough to drive a $300 \mathrm{~W}$ motor and the system will operate more than 7.5 hours a day. Thus, mSBAR can be the good alternative than existing BAR charged by the national grid. The SBAR is environment-friendly and eliminates human labor. There is no fuel consumption and it does not emit $\mathrm{CO}_{2}, \mathrm{CO}, \mathrm{UHC}$, and $\mathrm{SO}_{2}$ from the energy system. The Benefit-to-Cost analysis shows that the Benefitto-Cost Ratio is 6.69 and 7.22 for SBAR and m-SBAR whereas Benefit-to-Cost Ratio for the rest of cases is less than 2 . The payback period of $\mathrm{m}$-SBAR is 2.1 which is the lowest compared to the other cases. The technofinancial analysis indicates that the proposed $\mathrm{m}$-SBAR is financially feasible. It has also been found that microcontroller based DC motor control circuit improves battery lifetime in comparison to the traditional BAR. 


\section{Competing Interests}

The authors declare that they have no competing interests.

\section{Acknowledgments}

The project is funded in part by the Ministry of Science and Technology, Government of the People Republic of Bangladesh, under Grant no. 312/14-15.

\section{References}

[1] A. R. M. Siddique, A. A. Khondokar, M. N. H. Patoary, M. S. Kaiser, and A. Imam, "Financial feasibility analysis of a microcontroller based solar powered rickshaw," in Proceedings of the International Conference on Electrical Information and Communication Technology (EICT '13), pp. 1-5, Khulna, Bangladesh, February 2014.

[2] A. R. M. Siddique, S. N. Sakib, S. M. Tahsien, and M. S. Kaiser, "Performance evaluation of a microcontroller-based solar powered auto-rickshaw," in Proceedings of the 1st International Conference on Electrical Engineering and Information and Communication Technology (ICEEICT '14), pp. 1-6, Dhaka, Bangladesh, April 2014.

[3] M. S. Rahman, S. K. Saha, M. R. H. Khan, U. Habiba, and S. M. H. Chowdhury, "Present situation of renewable energy in bangladesh: renewable energy resources existing in bangladesh," Global Journal of Researches in Engineering Electrical and Electronics Engineering, vol. 13, no. 5, p. 1, 2013.

[4] N. Yasuda, Effects of long-term strenuous exercise on oxidative DNA damage and proteinuria in humans [Ph.D. Dissertations], The University of Montana, Professional Papers. Paper 362, 2007.

[5] S. Huque and R. K. Mazumder, "A concentrator PV power system in water pumping," in Proceedings of the National Seminar on Renewable Energy: Biomass/Bio Energy, Dhaka, Bangladesh, March 2006.

[6] K. Saifullah, "Load Shedding of Electricity in Bangladesh," 2010, http://freshclick.wordpress.com/2009/04/16/load-shedding-ofelectricity-in-bangladesh/.

[7] S. K. Nandi, M. N. Hoque, H. R. Ghosh, and S. K. Roy, "Potential of wind and solar electricity generation in Bangladesh," ISRN Renewable Energy, vol. 2012, Article ID 401761, 10 pages, 2012.

[8] World Automotive Achievements-Solar Powered Rickshaw, http://www.speedace.info.

[9] Wikipedia, Solar Energy, Wikipedia, http://www.wikipedia.org.

[10] M. Zaman, M. A. Islam, and M. A. R. Sarkar, "Two phase heat transfer in solar water heater," in Proceedings of the National Seminar on Renewable Energy: Biomass/Bio Energy, Dhaka, Bangladesh, March 2006.

[11] R. Ahmed, “Power crisis in Bangladesh," 2010, http://hubpages .com/hub/Power-crisis-In-Bangladesh.

[12] E. Kymakis, S. Kalykakis, and T. M. Papazoglou, "Performance analysis of a grid connected photovoltaic park on the island of Crete," Energy Conversion and Management, vol. 50, no. 3, pp. 433-438, 2009.

[13] M. S. Kaiser and A. R. M. Siddique, "Optimal hybrid option analysis for a remote location in Bangladesh," International Journal of Advanced Renewable Energy Research, vol. 2, no. 2, pp. 777-784, 2013.
[14] REEIN, "Solar Energy Program," Renewable Energy and Environmental Information Network (REEIN), 2010, http://www .reein.org/.

[15] J. L. Meriam and L. G. Kraige, Engineering Mechanics: STATICS (SI Version, 5th Edition), Wiley, New York, NY, USA, 5th edition, 2004.

[16] A. M. Eltamaly, K. E. Addoweesh, U. Bawa, and M. A. Mohamed, "Economic modeling of hybrid renewable energy system: a case study in Saudi Arabia," Arabian Journal for Science and Engineering, vol. 39, no. 5, pp. 3827-3839, 2014.

[17] "SREDA and Power Division Ministry of Power, Energy and Mineral Resources (MoPEMR) Government of the People's Republic of Bangladesh, Energy Efficiency and Conservation Master Plan up to 2030," http://www.sreda.gov.bd/index.php/ 1-downloads/8-eec-master-plan-sreda/file.

[18] JICA, "Ex-ante Evaluation (for Japanese ODA Loan), Bheramara Combined Cycle Power Plant Development Project (Engineering Service)," http://www.jica.go.jp/english/our work/evaluation/oda_loan/economic_cooperation/ c8h0vm000001rdjt-att/ban100324_02.pdf.

[19] M. Loster, “Total Primary Energy Supply- From Sunlight,” 2010, http://www.ez2c.de/ml/solar_land_area/. 


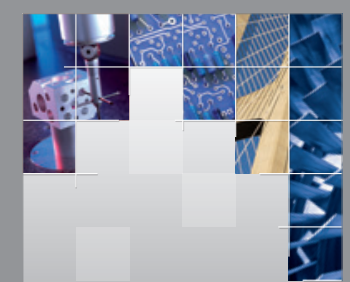

\section{Enfincering}
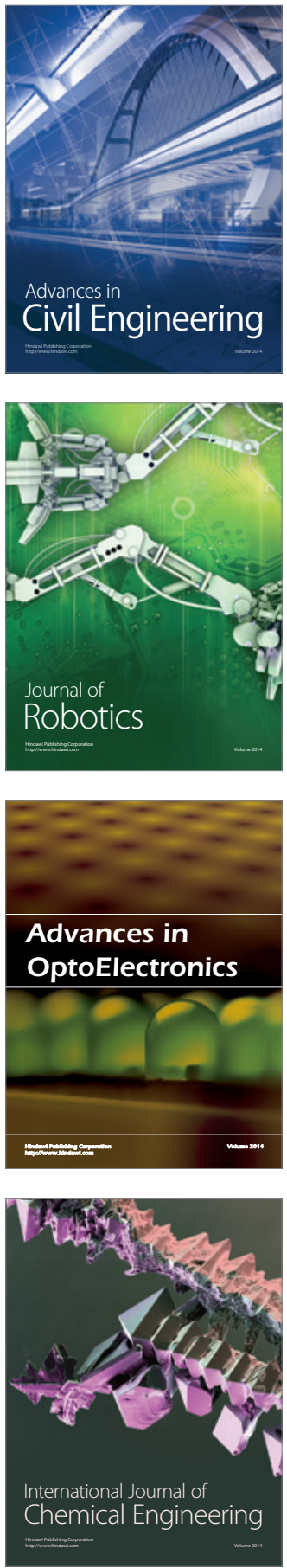

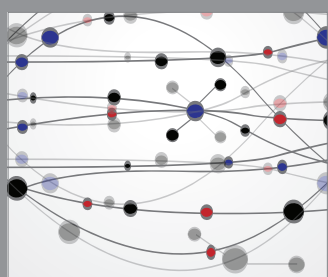

The Scientific World Journal

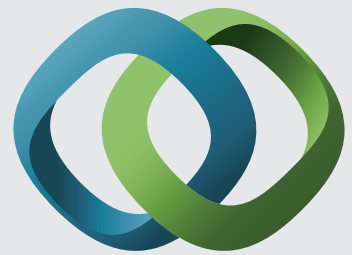

\section{Hindawi}

Submit your manuscripts at

http://www.hindawi.com
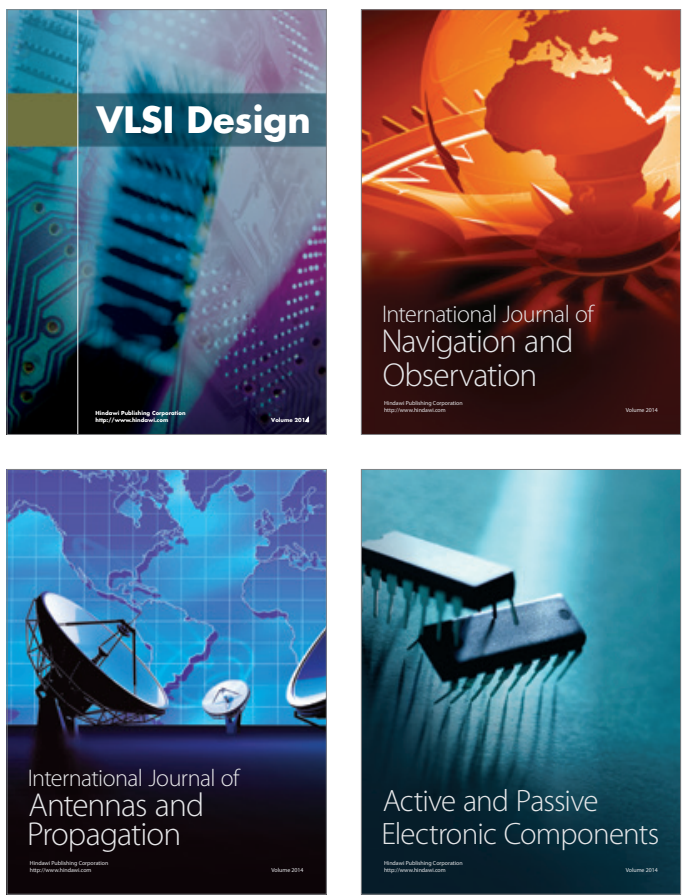
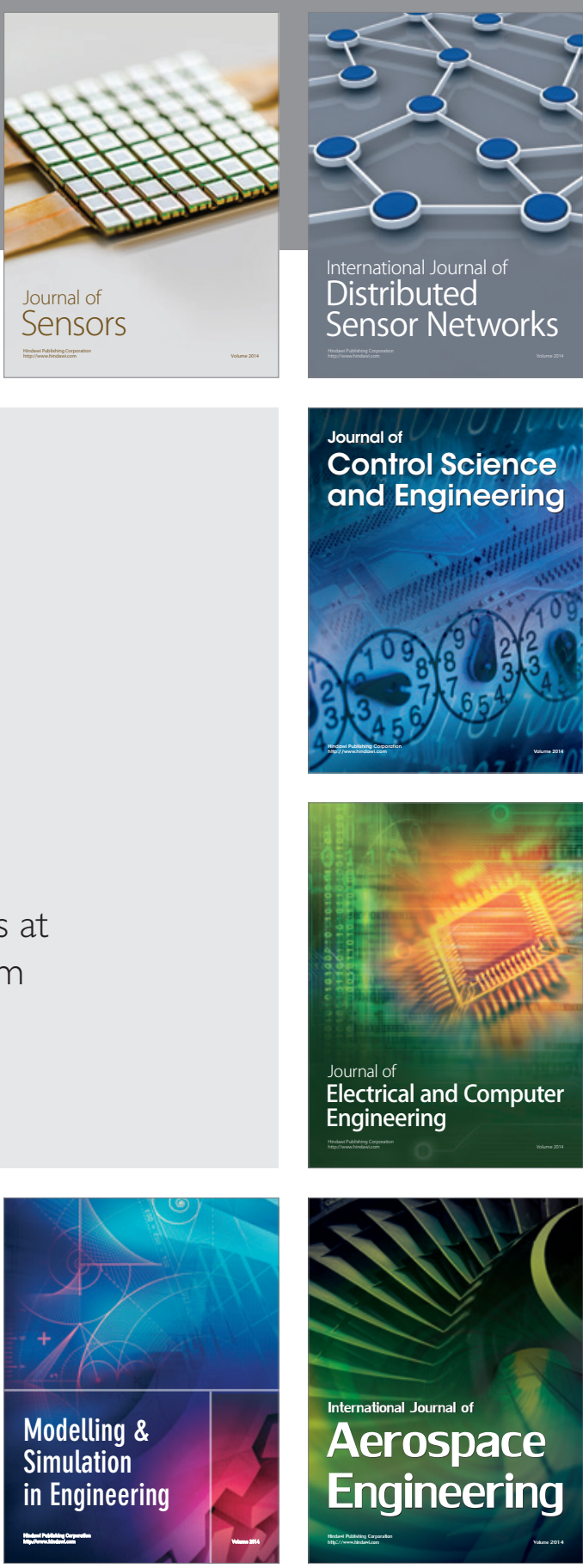

International Journal of

Distributed

Sensor Networks

Journal of

Control Science

and Engineering
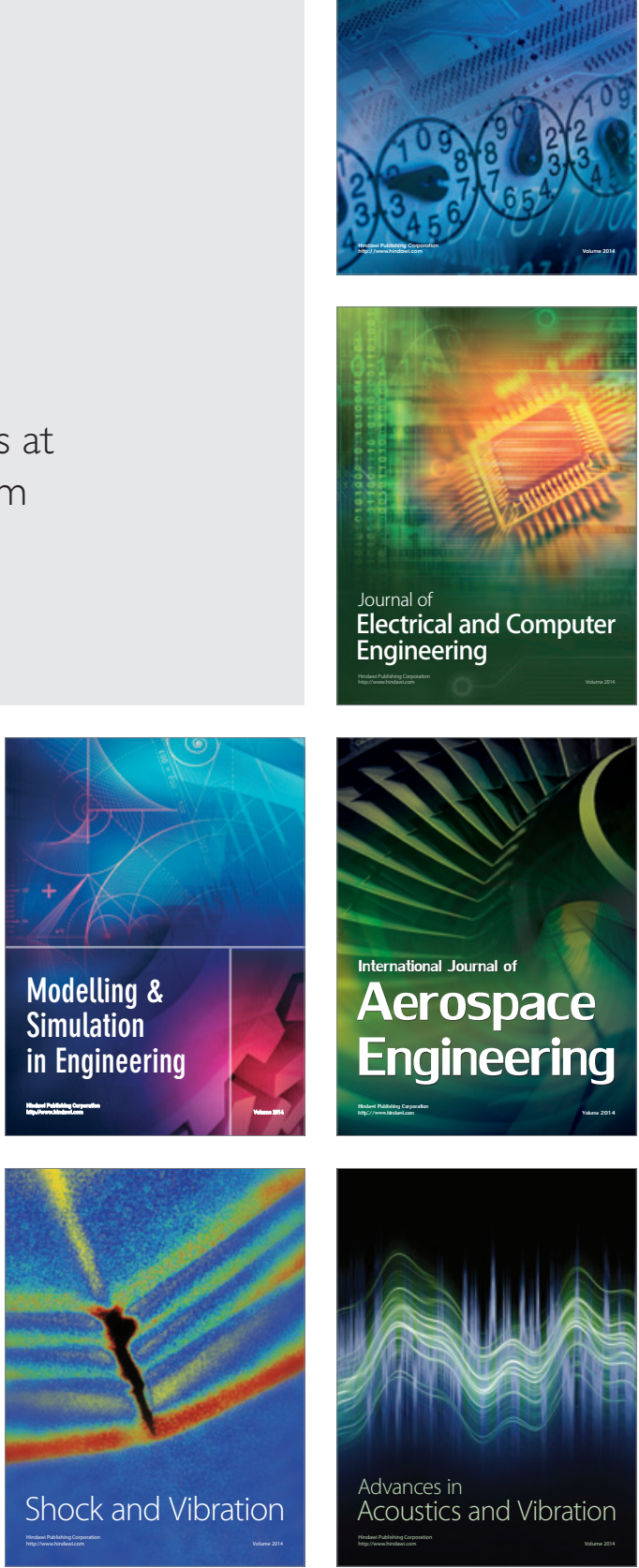